\title{
СТАНОВЛЕНИЕ МЕТОДОЛОГИИ ПОЗНАНИЯ В СОЦИАЛЬНО-ГУМАНИТАРНЫХ НАУКАХ И ГУМАНИЗМ*
}

\section{С.А. Нижников}

A.M. Opexoв

В статье рассматривается становление методологии познания в социально-гуманитарных науках, ее отпочкование от естественно-научного знания и связь с понятием гуманизма. Авторы обосновывают возможность применения понятия «научная революция» и к социально-гуманитарному знанию, выделяя два ее исторических этапа: «натуралистический» и «герменевтический». При этом вскрываются особенности и черты познания в гуманитарных науках, обосновывается их «онтология». В результате данной «революции» сформировались два типа онтологии: социальная и гуманитарная. Авторы рассматривают гуманизм как отправную точку формирования гуманитарной и гуманистической онтологии, и здесь от формального анализа они переходят к содержательному, определяя как понятие гуманизма, так и его возможные вариации. Прежде всего выделяются новоевропейский его вариант - антропоцентрический (возрожденческий) и теоантропоцентрический - восточнохристианский, исихастский (византийский). Специфика авторского подхода заключается в том, что осуществляется попытка наполнить гуманитарную онтологию гуманистическим содержанием, рассмотрев связанные с понятием гуманизма проблемы. Утверждается многообразие содержания гуманизма, которое определяется господствующей культурой, вскрывается кризис гуманизма в современности и выражается необходимость восстановления разорванного единства гуманизма с человечностью. Делается вывод о том, что исследование концепции научной революции в социально-гуманитарных науках может способствовать дальнейшей разработке не только гуманитарной, но и гуманистической онтологии.

Ключевые слова: герменевтика, методология познания в социально-гуманитарных науках, научная революция, социальная онтология, гуманитарная онтология, гуманизм.

\section{THE FORMATION OF THE METHODOLOGY OF COGNITION IN SOCIAL-HUMANITARIAN SCIENCES AND HUMANISM}

S.A. Nizhnikov

A.M. Orekhov

The article discusses the formation of the methodology of cognition in socio-humanitarian sciences, its budding from natural science knowledge, and its connection with the concept of humanism. The authors substantiate the possibility of applying the concept of "scientific revolution" to social and humanitarian knowledge, highlighting two of its historical stages: "naturalistic" and "hermeneutic". At the same time, the peculiarity and features of knowledge in humanitarian sciences reveals and their "ontology" unfolds. As a result of this "revolution" two types of ontology were formed: social and humanitarian. The authors consider humanism as a starting point for the formation of a humanitarian and humanistic ontology, and here they move from formal analysis to meaningful one, defining both the concept of humanism and its possible variations. First of all, its New-European version stands out - anthropocentric (Renaissance), and theoanthropocentric - Eastern Christian, hesychast (Byzantine). The specificity of the author's approach lies in the fact that an attempt is being made to fill the humanitarian ontology with humanistic content, having considered the problems associated with the concept of humanism. The diversity of the content of humanism, which is determined by the dominant culture, is affirmed; the crisis of humanism in modern times is revealed and the need to restore the torn unity of humanism with humanity is expressed. It is concluded that the study of the concept of the scientific revolution in the social and humanitarian sciences can contribute to the further development of not only humanitarian, but also humanistic ontology.

Keywords: hermeneutic, methodology of knowledge in socio-humanitarian sciences, scientific revolution, social ontology, hu-

\footnotetext{
* Исследование выполнено при поддержке Программы стратегического академического лидерства РУДН, гранта РФФИ и Министерства по науке и технологиям Тайваня в рамках научного проекта 20-511-S52002 MHТ а «Философия человека как проблема междисциплинарных исследований».
}

Нижников Сергей Анатольевич - доктор философских наук, профессор кафедры истории философии факультета гуманитарных и социальных наук Российского университета дружбы народов (г. Москва).

Nizhnikov Sergei Anatolyevich - D.Sc. (Philosophy), Professor of History of Philosophy Department at Peoples' Friendship University of Russia (Moscow).

E-mail: nizhnikov-sa@rudn.ru

Орехов Андрей Михайлович - доктор философских наук, доцент кафедры социальной философии факультета гуманитарных и социальных наук Российского университета дружбы народов (г. Москва).

Orekhov Andrey Mikhailovich - D.Sc. (Philosophy), Associate Professor of Social Philosophy Department at Peoples' Friendship University of Russia (Moscow).

E-mail: orekhovandrey@yandex.ru 
manistic ontology, humanism.

1. От натуралистической к герменевтической методологии: от Огюста Конта к Максу Веберу

«Научная революция», согласно работе Т. Куна (Kuhn T., 2002), - это коренной переворот в науке, радикальная смена научных парадигм. Классическими примерами революций в естественных науках служат: первая - ньютонианская XVII-XVIII вв., вторая - эйнштейновская начала XX в., когда появилась квантовая механика, специальная и общая теории относительности. Другой пример - коперниканская революция в астрономии XVI-XVII вв. положившая конец представлениям о неподвижности Земли и заложившая основы теории бесконечной Вселенной (Н. Кузанский, Д. Бруно).

А как быть с развитием методологии познания в социально-гуманитарных науках?

Здесь можно дать следующее определение: «научная революция» в истории социально-гуманитарного знания - это радикальная, коренная трансформация исходных представлений всего этого знания, переход от одной парадигмы в социальногуманитарном знании к другой. В.С. Степин выделял в развитии методологии научного познания три периода: классический (XVII-XIX вв.), неклассический (в основном XX в.), и современный - постнеклассический [14]. Тогда в развитии методологии социально-гуманитарного знания по аналогии можно выделить два периода: неклассический (конец XIX - начало XX в.) и постнеклассический (конец $\mathrm{XX}$ - начало XXI в.). Отправной точкой для аргументации в пользу таких революций являются качественные изменения в типах рациональности [13: с. 80]. Такое революционное изменение можно определить как «герменевтическую революцию».

Но одним из авторов этой статьи была предложена альтернативная точка зрения на проблему научных революций в социально-гуманитарных науках. Им утверждалось, что в истории социальногуманитарного знания мы можем проследить всего лишь одну научную революцию - «КМВ-революцию», и совершалась она в течение примерно 80 лет ориентировочно с 1840 по 1920 г. [7: с. 15-22]. «КМВ» здесь означает «Конт-Маркс-Вебер». Основные вехи этой революции: выход работы О. Конта «Курс позитивной философии» (1830-1842), фундаментального труда К. Маркса «Капитал» (1867) и других работ, и, наконец, методологических статей М. Вебера (1904-1920), опиравшегося на традицию неокантианства. «КМВ-революция» заложила основы для герменевтического поворота в методологии познания в области социальногуманитарного познания.

В результате произошел переход от «натуралистического» периода развития социально-гумани- тарных наук» к «герменевтическому», сформировавший их современную структуру, определивший динамику развития вплоть до современной эпохи постмодерна.

Произошли следующие коренные изменения:

(1) разделение социально-гуманитарного знания на социальное и гуманитарное;

(2) формирование позитивизма - первой инновационной и полномасштабной методологии социально-гуманитарного знания, которая в слегка измененном виде («логический позитивизм», «неопозитивизм», «постпозитивизм») продолжает доминировать в современных социально-гуманитарных науках;

(3) осознание роли идеологии как конститутивной функции этого знания, идеологии как института и формы общественного сознания, которая, с одной стороны, формирует «социальный» и «идеологический заказ» как на само социальногуманитарное знание, так и на его практическую реализацию, а с другой, сама является результатом его развития [8: с. 87].

Автором понятия «идеология» является А. Дестютом де Траси. Хотя смысл концепта «идеология» оказался с начала XIX в. измененным, само появление этого понятия в данный исторический период (т.е. непосредственно предшествующий «герменевтической революции») следует считать примечательным: ведь оно, это понятие, сыграло роль медиатора в осмыслении той связи, которую могут установить между собой «общество» и «социально-гуманитарные науки». Пока же в натуралистический период мы наблюдаем разрыв и даже пропасть между этими институтами: они существуют на разных полюсах, и даже как бы «не ведают» о существовании друг друга. Ситуацию можно выразить также следующей геометрической метафорой: эти институты (общество и социальногуманитарные науки) развиваются параллельно, как евклидовы прямые, и в натуралистический период они еще никак не могут пересечься. И лишь «неэвклидова ситуация» (т.е. пересечение параллельных) герменевтического периода (включая рождение идеологии) радикально меняет дело: полюса сходятся, социально-гуманитарное знание становится инструментом идеологии и политики, а идеология и политика получают новые импульсы развития от социально-гуманитарного знания.

В итоге натуралистический период в эволюции социально-гуманитарного знания можно расценивать как первоначальную фазу его эволюции в обществе, а влияние этого типа знания на общество в целом и частные социальные структуры последнего можно полагать незначительным и не заслуживающим серьезного внимания. 
Герменевтический период в социально-гуманитарных науках характеризуется разделением социального и гуманитарного знания и стремлением к конструированию двух разных методологий - социальной и гуманитарной. Начиная с конца XIX в. социальное и гуманитарное знание двигаются по расходящимся траекториям ${ }^{1}$, формируя собственные исследовательские стратегии постижения социально-гуманитарного мира. Например, анализ проблемы суицида у Э. Дюркгейма косвенным образом указал на возможность различения социальных и гуманитарных фактов [17], а развитие герменевтической, социально-феноменологической, постструктуралистсткой и постмодернистской философии сформировало базисные основы гуманитарной исследовательско-методологической программы. При этом социальные и гуманитарные науки, помимо ставшего уже привычным их взаимодействия с естественными, логико-математическими и техническими науками, также активно взаимодействуют между собой, а сама оппозиция «социального» и «гуманитарного» трансформируется в сложные и иногда весьма запутанные типы междисциплинарного взаимодействия и междисциплинарного синтеза 2 .

С творчества К. Маркса кардинально меняется понимание взаимоотношения между «обществом» и «социально-гуманитарными науками»: последние начинают рассматриваться как инструмент, орудие влияния и манипулирования массами, а также как средство публичной политики и идеологического воздействия:

«Карл Маркс рассматривал идеологию в качестве важного фактора воспроизводства капиталистического класса. Он утверждал, что господствующие группы способны контролировать и господствующие идеи, циркулирующие в обществе, легитимируя тем самым свою привилегированную позицию... Марксисты полагали, что социальный анализ должен раскрывать искажения идеологии» [1: c. 223].

В этом смысле позиция К. Маркса имела немало общего с «позитивизмом» О. Конта; можно даже сказать, что он развивает и продолжает контовское

\footnotetext{
1 Этот факт подчеркивали многие исследователи, например К. Леви-Стросс во втором томе «Структурной антропологии» (Lévi-Strauss C. Structural Anthropology. Vol. II. London, Basic Books, 1976).

2 Так, Ю. Иванова, выражая взгляд на данную проблему со стороны гуманитарного знания, пишет: «В XIX-XX вв. оппозиция дисциплинаризации станет своего рода лейтмотивом истории гуманитарных наук». Крейцер и Ницше, Шеллинг и Гадамер выступят с «декларациями о необходимости философского преобразования гуманитарного знания». А Хайдеггер и вовсе скажет: «Наука не мыслит» (Иванова Ю. «История идей» и «гражданская наука»: границы дисциплинарности в раннее Новое время // Наука о человеке: история дисциплин. Москва : Издат. дом ВШЭ, 2015).
}

понимание активности всякого социального знания, включая социологическое знание: «Сама социология есть продукт модерна. Ее цель - получить с помощью научных методов надежное знание о социальном мире для того, чтобы вмешиваться в жизнь общества и улучшать ее на благо всем» [1: с. 24-25].

Но в герменевтический период социальногуманитарное знание не только «активно», оно еще и «рефлексивно», - социальные ученые и ученыегуманитарии начинают размышлять над истоками этого типа знания, его природой, сущностью и т.п., тем самым избавляясь от «априорности» и «догматизма» в его понимании. Следует предположить, что, меняя свое отношение к обществу и становясь целенаправленной силой социальных преобразований, социально-гуманитарное знание способно со временем инициировать радикальную трансформацию в отношении самого себя, - хотя вектор этой трансформации, - вследствие эволюционного характера герменевтического периода, - остаётся по своим результатам неопределенным, размытым и непредсказуемым.

В итоге герменевтический период в эволюции социально-гуманитарного знания отразил в себе радикальные изменения как в содержании социально-гуманитарного знания, так и в его роли в общественных трансформациях. Этот период продолжается и поныне, в XXI в.

Расхождение между собой социальных и гуманитарных наук привело к формированию двух различных и даже по-своему полярных типов онтологии социальной онтологии и гуманитарной онтологии.

\section{2. Понятие гуманитарной онтологии}

В современной научной литературе не существует недостатка в определениях того, что есть социальная онтология. Например, авторитетный в этой области американский философ Брайан Эпштейн определял ее следующим образом: «Социальная онтология - это попытка прояснить позицию социальных наук в отношении следующих проблем: намерения социальных групп, социальные законы, собственность, институты и т.п.» [18: p. 149].

Авторы статьи определяют социальную онтологию несколько иначе, ближе к ее «субстанциональному» аспекту: социальная онтология - это учение о базовых принципах устройства социальной реальности, основанное на междисциплинарных и трансдисциплинарных стратегиях исследования социального мира. В этом определении подчеркивается междисциплинарный, кроссдисциплинарный и трансдисциплинарный характер социальной онтологии и, в частности, несводимость ее к конкретным дисциплинарным типам онтологии (например, к социологической онтологии или экономической онтологии). 
В противовес социальной онтологии гуманитарная онтология должна быть определена как учение о базовых принципах устройства гуманитарной реальности, основанное на междисциплинарных и трансдисциплинарных стратегиях гуманитарного мира.

Здесь важно указать на следующие значимые пункты:

(а) гуманитарная онтология, в отличие от социальной, концентрируется, прежде всего, на междисциплинарных дискурсах человека на фоне всей социально-гуманитарной реальности, используя в качестве основного объекта исследования «текст» и «коммуникацию», дополняя их анализом индивидуальных, особенных, уникальных характеристик человеческой личности. Основной метод гуманитарной онтологии - интерпретация; вместе с другими методами (деконструкция, шизоанализ и др.) она конструирует полномасштабную онтологическую картину гуманитарной реальности на фоне всех социальных трансформаций рубежа XX-XXI вв.;

(б) гуманитарная онтология, в отличие от социальной, стремится разработать собственный дискурс, глубинно отличающийся от методологии не только естественно-научного, но даже социального познания;

(в) гуманитарная онтология интересуется больше уникальным и индивидуальным, а не только всеобщим и необходимым;

(г) она диалогична и коммуникативна в гораздо большей степени, чем естественные и социальные науки;

(д) в ней присутствует свобода, которой нет в мире физическом и биологическом, она существует только в мире социальном, личностном [21: p. 100];

(е) гуманитарная онтология плюралистична: в ней действуют минимум пять исследовательских программ.

Под программой в гуманитарной онтологии следует понимать совокупность когнитивных и методологических установок, демонстрирующих оригинальное и самобытное понимание природы гуманитарной реальности, а также - структурного поля гуманитарной онтологии, задач и целей гуманитарно-онтологического исследования.

Как предполагают авторы статьи, в современной гуманитарной онтологии действуют пять основных программ:

(a) социальный конструктивизм (П. Бергер, Н. Лукман, Б. Латур и др.);

(б) постструктурализм (М. Фуко, Ж. Бодрийяр, П. Бурдье и др.);

(в) герменевтика (Х.-Г. Гадамер, П. Рикёр и др.);

(г) психоанализ (Ж. Лакан, Ж. Батай и др.);

(д) постмодернизм (Ф. Лиотар, Ж. Делез, Ф. Гваттари, Ж. Деррида и др.).
Основные позиции, которые изучает гуманитарная онтология, следующие: «тексты и любые языковые источники, а также их интерпретации»; «коммуникация и диалог»; «деятельность человека по социальному конструированию окружающей его реальности»; «культурные объекты и символы, с ними связанные»; «гуманитарные артефакты и деятельность по их созданию»; «бессознательное, психоанализ и шизоанализ».

Таким образом, в современной гуманитарной онтологии мы наблюдаем конкуренцию различных исследовательских программ («конкуренцию программ» - в том представлении, что было у И. Лакатоса): эти программы ведут между собой нескончаемую борьбу за лидерство в гуманитарном знании. Например, можно предполагать, что в 80-90-е гг. $\mathrm{XX}$ в. первенство здесь оставалось за постмодернизмом (хотя многие исследователи могут оспаривать этот факт). Причем следует обратить внимание на интересный факт, что за материалом для своего анализа представители гуманитарной онтологии часто обращались к социальным мыслителям и социальной онтологии. В частности, это касается решения классической проблемы «равенство и справедливость» и понимания справедливости в ее дистрибутивном аспекте [16: р. 604-610], где свое слово, к примеру, высказал П. Рикёр [10].

\section{3. Гуманизм как сущностная составляющая гуманитарной онтологии}

Эпоха Ренессанса (иначе - эпоха Возрождения) это исторический период, относящийся примерно к XIV-XVI вв., и страной, где Возрождение достигло своей максимальной зрелости, считается Италия. Начиналась данная эпоха как возрождение интереса к античности, Древней Греции и Древнему Риму, классикам древнегреческой и древнеримской философии, и особенно к нравственному содержанию их текстов: «Нравственное содержание [древнегреческих и древнеримских] классических текстов выдвигало на первый план вопросы, касающиеся благоразумия и правильного поведения» [11: с. 23]. Также, как отмечает В.В. Соколов: «Страстный интерес к античности сделал гуманистов блестящими знатоками латинского классического языка..., возрождение которого стало само по себе критикой господствовавшей церковно-схоластической учености...» [12: с. 14].

Этимологически слово «гуманизм» восходит к латинскому humanus - «человеческий», «человечный» и является производным от homo - человек. Человечность, в свою очередь, можно определить как моральность. Именно мораль, как утверждал еще И. Кант, формирует человека как homosapience, именно ее наличием он в наибольшей степени отличается от животного мира. Моралью же 
является то, что «выпадает в осадок» в результате духовного познания [6: с. 64]. Как и мировоззрение, гуманность обычно определяется господствующей в обществе идеологией. Что касается эпохи Возрождения, то, «как подразумевает само слово “гуманизм", это было движение, поместившее человека в центр внимания и воспевшее его способность, вдохновленную античными образцами, открывать в себе великие качества» [11: с. 22].

Выявив гуманизм как понятие, в дальнейшем можно анализировать его конкретные проявления в той или иной культуре, уже не в широком, а узком и специфическом смысле слова: от человечности как таковой можно перейти к ее конкретным воплощениям и образам в различных культурах. Одним из таких практических воплощений будет гуманизм как идейное течение внутри эпохи Возрождения, другим гуманизм, например, в древнегреческих классических полисах, когда софист Протагор провозгласил, что «человек есть мера всех вещей». В этой связи стоит отметить, что гуманистические идеи в той или иной степени рождаются уже в «осевую эпоху» (К. Ясперс). Однако античный гуманизм в целом был ограничен как космо- и социоцентризмом, так и рабовладением, а возрожденческий - своим богоборческим посылом, доходящим до воинствующего антропоцентризма, когда ведущим принципом стал гедонизм, пришедший на смену средневековому аскетизму. В мировоззренческом плане средневековый трансцендентизм сменился вначале пантеизмом, а затем материализмом и атеизмом. Человек стал мыслиться уже не как божественное творение, которому следует стремиться к духовно-нравственному совершенству, а как наследник приматов, которому следует без зазрения совести свободно реализовывать все свои биологические инстинкты. Свобода оторвалась от добродетели и стала рассматриваться как вседозволенность.

Но уже в рамках эпохи Ренессанса делается первый, хотя еще робкий шаг в направлении разделения социальных и гуманитарных наук - еще весьма отдаленной предпосылки герменевтической революции. По мнению Р. Смита, само рождение концепта «гуманитарная наука» следует соотносить с началом и дальнейшим расцветом гуманистического движения в Италии и, в целом, в Европе: «...упор делался на изучение наук, которые историки сегодня иногда называют studia humanitatis, или гуманитаристикой: grammatica, rhetorica, poetica, historia и philosiophia moralis» [11: c. 24].

Но еще до эпохи Ренессанса, в Византии XI-XIV вв. появляется и развивается особого вида гуманизм, тоже руководствующийся антропным принципом, но не отрицающий теизм, а, напротив, утверждающий перспективу обо́жения человека, своеобразный антропоцентризм в рамках теоцен- тризма, - теоантропоцентризм. Вклад этого типа гуманизма в формирование гуманитарной онтологии также следует признать заслуживающим внимания; причем необходимо указать на тот факт, что вклад этот был внесен этим типом гуманизма еще до эпохи Ренессанса и «герменевтической революции».

Связан этот процесс с понятием исихазма, возникшего на заре христианства, молитвенная практика которого была догматически оформлена в Византии в XIV в. Если возрожденческий гуманизм в итоге сместил Бога и на его место водрузил человека со всеми его недостатками и эгоизмом, то исихастский говорит о возможности обо́жения человеческой природы - максимального и бесконечного уподобления человека абсолютной и совершенной божественной Личности. В этом случае сохраняется этический Абсолют, к которому следует стремиться, и происходит облагораживание самого человека, развертывание его сущности в духовном бого- и самопознании, формируется истинная человечность. Ведь сущность человека человечна, она может раскрыться лишь в результате трансцендирования его биологической природы, выхода за пределы собственного эгоизма. Так, обращением к трансцендентному (Богу) вскрывается имманентное (сущность человека) - человечность.

В Византии XI в. получают развитие раннехристианские идеи и молитвенная практика, прежде всего - в жизни и творчестве Симеона Нового Богослова, и закрепляются в догматике благодаря деятельности Григория Паламы. Но исторические события препятствовали его развитию, а наследница Византии - Русь - еще не была готова в полной мере раскрыть этот духовный дар в силу обстоятельств исторического характера. Идеи же итальянского Ренессанса попали в благодатную почву и выросли в новоевропейскую культуру.

Однако в русской метафизической мысли ренессансный гуманизм был подвергнут критике как человекобожеский, и разрабатывался его богочеловеческий вариант, во многом повторявший византийский опыт исихазма [15: с. 415]. Наследники Владимира Соловьева - Сергий Булгаков, Павел Флоренский и др. - указывали, что в основе богоборческого гуманизма лежит человеческая гордыня и эгоизм, что может привести к моральной деградации, чреватой как деформацией личности, так и глобальными проблемами. Николай Бердяев полагал, что необходимо «раскрытие положительной правды о человеке, о его творческом признании» [9: с. 220]. Трагические события в России 1917 г. дали толчок к осознанию последователями Вл. Соловьева, что «безрелигиозный гуманизм есть самоутверждение человека, обоготворившего себя, своеволие, которое должно привести к распаду об- 
щественности, как это давно уже провидел Достоевский» [5: с. 287].

В результате сказанного можно прийти к выводу, что гуманизм может проявляться в разных формах, светских и религиозных, которые могут быть далеко не идеальны. В современном мире необходимо стремиться наследовать все лучшее из различных его форм, не столько противопоставляя, сколько объединяя людей в борьбе с общими вызовами и угрозами. Для этого следует восстановить разорванное единство гуманизма с человечностью. Надеемся, что исследование концепции «герменевтической революции» в социально-гуманитарных науках будет способствовать дальнейшей разработке не только гуманитарной, но и гуманистической онтологии.

\section{ЛИТЕРАТУРА}

1. Гидденс, Э. Основные понятия социологии / Э. Гидденс, Ф. Сатто. - Москва : Издат. дом ВШЭ, 2018.

2. Иванова, Ю. «История идей» и «гражданская наука»: границы дисциплинарности в раннее Новое время / Ю. Иванова // Наука о человеке: история дисциплин. - Москва : Издат. дом ВШЭ, 2015.

3. Каубе, Ю. Макс Вебер: жизнь на рубеже эпох / Ю. Каубе. - Москва : Дело, 2016.

4. Кун, T. Структура научных революций / Т. Кун. Москва : АСТ, 2003.

5. Лосский, Н. Преемники Вл. Соловьева / Н. Лосский // Путь. Орган русской религиозной мысли (№ 3. 1926). Москва : Информ-Прогресс, 1992. - С. 277-287.

6. Нижников, С.A. Духовное познание в философии Востока и Запада / С.А. Нижников. - Москва : Изд-во РУДН, 2009.

7. Орехов, А.М. КМВ-революция и ее значение для понимания эволюции современного социально-гуманитарного знания / А.М. Орехов // Право и государство: теория и практика. - 2020. - № 11. - С. 15-22.

8. Орехов, А.М. Социальная философия: предмет, структурные профили и вызовы на рубеже XXI века / A.M. Opeхов. - Москва : УРСС, 2011
9. Публичное заседание Религиозно-философской академии, посвященное памяти Владимира Соловьева // Путь. Орган русской религиозной мысли (№ 2, 1926). - Москва : 1992. - C. 219-221.

10. Рикер, П. Справедливое / П. Рикер. - Москва : Логос-Гнозис, 2005.

11. Смит, Р. История гуманитарных наук / Р. Смит. Москва : Издат. дом ВШЭ, 2007.

12. Соколов, В.В. Европейская философия XV-XVII вв. / В.В. Соколов. - Москва : Мысль, 1984

13. Степин, В.С. Картина мира и современные проблемы научного знания / В.C. Степин // Культурноисторическая эпистемология: Проблемы и перспективы. Москва : РОССПЭН, 2014. - С. 75-90.

14. Степин, В.С. Теоретическое знание / В.С. Степин. Москва : Прогресс-Традиция, 1999.

15. Франк, С.Л. Свет во тьме / С.Л. Франк // Духовные основы общества. Введение в социальную философию. Москва : Республика, 1992. - С. 13-146.

16. Chernyak, A.Z. Egalitarian Distributive Justice and Reasoning Luck / A.Z. Chernyak // Proceedings to the International Conference on Contemporary Education, Social Sciences and Humanities (ICCESSH 2016). - Paris, Atlantis Press, 2016. P. 604-610.

17. Durkheim, E. Suicide: A Study in Sociology / E. Durkheim. - London, Taylor \& Francis e-Library, 2005.

18. Epstein, B. A Framework for Social Ontology / B. Epstein // Philosophy of Social Sciences. - 2016. - Vol. 46, № 2. P. 147-167.

19. Epstein, B. Social Ontology / B. Epstein // Stanford Encyclopedia of Philosophy. - 2021. - 12.01. - URL: http://plato. stanford.edu/entries/social-ontology (accessed 28.01.2021).

20. Lévi-Strauss, C. Structural Anthropology. Vol. II / C. Lévi-Strauss. - London : Basic Books, 1976.

21. Nizhnikov, S. Neo-Kantianism and specificity of "sciences of the spirit" / S. Nizhnikov, Le Thi Tuyet // Proceedings of the 4-nd International Conference on Contemporary Education, Social Sciences and Humanities (ICCESSH 2019). - Paris : Atlantis Press, 2019. - P. 98-102. 